\title{
Maternal Mortality: How Far with the Reduction Battle?
}

\section{Aniefiok J Umoiyoho*}

Community Obstetrics, University of Uyo, Akwa Ibom State, Nigeria

In the International Statistical Classification of Diseases and Related Health Problem, 10th revision, (ICD-10), WHO defines maternal mortality as The death of a woman while pregnant or within forty two days of termination of pregnancy, irrespective of the duration and the site of the pregnancy, from any cause related to or aggravated by the pregnancy or its management but not from accidental or incidental causes, an announcement by WHO on behalf of the United Nations of the latest global estimates, published in May 2012, showed that the trend in maternal death appears to be falling overall [1]. A study published in the Lancet shows a significant drop worldwide in the number of mothers dying during pregnancy or childbirth [2]. But while the overall news may be positive, conditions in Africa remain at emergency levels. The Lancet study revealed that in 2008, six countries accounted for nearly half of all maternal mortality cases. Three of them, Ethiopia, Nigeria and The Democratic Republic of Congo are in Africa.

Globally, an estimated 287000 maternal deaths occurred in 2010, a decline of $47 \%$ from levels in 2009. Sub-Saharan Africa (56\%) and Southern Asia (29\%) accounted for $85 \%$ of the global burden $(245000$ maternal deaths) for that year [3]. In the same year at the country level, two countries account for a third of the global maternal deaths; India at $19 \%(56000)$ and Nigeria at $14 \%(40000)$. Yet the rate of reduction of maternal deaths in these countries like Nigeria that contributed the highest to global maternal death burden is the slowest and is described as inadequate [4]. Even the so called reduction may not be truly so as the strategies and means for the reduction of maternal mortality like improved health services, poverty reduction strategies, skilled maternity care with required equipment, improved, accessible and affordable antenatal care and women empowerment are yet to be seen to have improved significantly in these Regions. It is also difficult to say categorically that the reported figures are the true reflection of the facts on ground because of lack of reliable information from these developing countries. The International Community should therefore pay more attention to these countries so that the maternal mortality effort does not go the way of "Health for all by the year 2000".

\section{References}

1. Berer M (2012) Trends in maternal mortality1990-2010: Latest data. Reproductive Health Matters.

2. African Maternal Mortality Defies Global Trend (2012). VOA News, April.

3. World Health Organization, UNICEF, UNFPA, The World Bank (2012) Trends in Maternal Mortality: 1990 to 2010: WHO, UNICEF, UNFPA and The World Bank estimates: 59 .

4. Agan TU, Archibong El, Ekabua JE, Ekanem El, Abeshi SE, et al (2010) Trends in Maternal Mortality at the University of Calabar Teaching Hospital, Nigeria 1999-2009. Int J Womens Health 2: 249-254.
*Corresponding author: Aniefiok J Umoiyoho, Community Obstetrics, University of Uyo, Akwa Ibom State, Nigeria, E-mail: draniiyoho@yahoo.com

Received October 26, 2012; Accepted October 31, 2012; Published September 07, 2012

Citation: Umoiyoho AJ (2013) Maternal Mortality: How Far with the Reduction Battle? J Socialomics 2: e111. doi:10.4172/2167-0358.1000e111

Copyright: ( 2013 Umoiyoho AJ. This is an open-access article distributed under the terms of the Creative Commons Attribution License, which permits unrestricted use, distribution, and reproduction in any medium, provided the original author and source are credited. 